\title{
Conselho de saúde do Distrito Federal: uma análise documental
}

\author{
Federal District Health Council: a documentary analysis \\ Consejos de Salud en el Distrito Federal: un análisis documental
}

\section{Marina Lessa Gomes ${ }^{1}$ Sandra Mara Campos Alves²}

RESUMO: Este estudo tem como objetivo geral discutir as principais mudanças ocorridas nos dispositivos legais que regulamentam o Conselho de Saúde do Distrito Federal à luz da Lei $n^{\circ}$ 8.142/90. Trata-se de análise documental acerca das alterações legais do Conselho de Saúde do DF. A técnica de análise utilizada foi a análise documental. Os dados foram analisados tomando-se como base as seguintes temáticas: composição, com enfoque na representatividade e na paridade; atribuições; autonomia e participação nas decisões políticas. Demonstrou-se que tanto a origem quanto a evolução do Conselho de Saúde do DF estão associadas aos diversos momentos históricos que o país vivenciou. As principais alterações nos instrumentos legais do Conselho de Saúde do DF surgiram como tentativas de atender a demandas trazidas a partir da promulgação das Leis 8080/1990 e 8142/1990. Observam-se limitações nos textos dos atos analisados, pois, desde a implementação do SUS, houve quatro alterações significativas com o objetivo de alterar a estrutura, a composição e as competências do Conselho de Saúde do DF. Nota-se ainda acentuada demora na regulamentação das alterações legislativas para conformar-se com a Constituinte, bem como com os dispositivos legais do âmbito federal. Somente a existência dos dispositivos legais não assegura a existência concreta do conselho, além disso, não se constitui necessariamente em efetiva participação social no SUS.

Palavras-chave: Participação Social. Controle Social na Saúde. Democracia Participativa.

ABSTRACT: This study has the general objective to discuss the major changes in the legal provisions governing the Federal District Health Council in light of Law No. 8,142 / 90. This is a documentary analysis about the legal changes in the Health Council in the Federal District. The analysis technique used was documentary analysis. Data were analyzed on the basis of the following topics: composition, focusing on the representation and parity; assignments; autonomy and participation in political decisions. The results show that both the origin and evolution of the Health Council of the FD is associated with many historical moments that the country experienced. The main changes in the legal instruments of the Health Council of the FD emerged attempting to meet demands brought from the enactment of Laws 8080/1990 and 8142/1990. Limitations were observed in the texts of the acts that were analyzed, because since the implementation of SUS, there have been four significant changes in order to change the structure, composition and powers of the Health Council in FD. We also noted a marked delay in the regulation of legislative changes to conform with the constitutional and legal provisions in the Federal level. The existence of

\footnotetext{
${ }^{1}$ Enfermeira, Secretaria de Saúde do DF; possui formação em Enfermagem pela Escola de Enfermagem da Universidade Federal da Bahia (UFBA). Email: maria.lessa.gomes@gmail.com

${ }^{2}$ Advogada, Especialista em Direito Sanitário pela Fiocruz/Brasília, Mestre em Política Social pela UnB e pesquisadora colaboradora do Programa de Direito Sanitário da Fiocruz/Brasília, Doutoranda em Saúde Coletiva pela UnB. Email. smcalves@gmail.com
} 
legal provisions not only doesn't ensure the concrete existence of the council, moreover, doesn't necessarily constitute an effective social participation in the SUS.

Keywords: Social Participation. Social Control on Heal. Democracy

Resumen: Este estudio tiene como objetivo general discutir los cambios importantes en las disposiciones legales que rigen el Consejo de Salud del Distrito Federal a la luz de la Ley $\mathrm{N}$ - 8.142 / 90. Se trata de un análisis documental acerca de las alteraciones legales del Consejo de Salud en el Distrito Federal. La técnica de utilizada fue el análisis documental. Los datos fueron analizados con base en los siguientes temas: la composición, la cual se centra en la representación y la paridad; atribuciones; autonomía y participación en las decisiones políticas. Los resultados muestran que tanto el origen como la evolución del Consejo de Salud del DF se asocia con diversos momentos históricos que el país experimentó. Las principales alteraciones en los instrumentos jurídicos del Consejo de la Salud del Distrito surgieron para intentar satisfacer las demandas que aparecieron desde la promulgación de las Leyes 8080/1990 y 8142/1990. Se observaron limitaciones en los textos de los actos analizados, ya que desde la implementación de SUS, ha habido cuatro cambios significativos con el objetivo de alterar la estructura, composición y competencias del Consejo de Salud en el Distrito Federal. Se observa también una acentuada demora en la reglamentación de las alteraciones legislativas para conformarse como Constituyente, con dispositivos legales en el ámbito Federal. La existencia solamente de dispositivos legales no asegura la existencia concreta del consejo, además de eso, no constituye necesariamente una efectiva participación social en SUS.

Palabras-Ilave: Participación social. Control social en la salud. Democracia

\section{Introdução}

No Brasil, a organização social esboçada na Constituição Federal de 1988 prevê a participação do povo na gestão pública, por via institucional ou não. É a prevalência da vontade do povo sobre aquela de qualquer indivíduo ou grupo, por democracia implicar autogoverno e exigir que os próprios governados decidam sobre as diretrizes políticas fundamentais do Estado (1).

O movimento de Reforma Sanitária Brasileira (RSB), ao demandar a garantia do direito à saúde como componente da cidadania, indicava um conjunto de mudanças no Estado, visando melhoria da situação de saúde e das condições de vida da população. Como parte dessa totalidade de mudanças, defendia o princípio de que a saúde era direito de todos e dever do Estado e propunha a instalação de um Sistema Único de Saúde (SUS), democrático e descentralizado, com responsabilidades estabelecidas para as três esferas de governo (2).

A inclusão do direito à saúde como direito universal no texto constitucional de 1988 foi importante conquista no processo de construção da cidadania brasileira e significou a 
incorporação de outras dimensões relevantes no campo da democracia, como a reafirmação do direito ao trabalho, liberdade de expressão e reorganização do Estado por meio da redefinição do pacto federativo com ênfase na descentralização das políticas públicas e na participação social (3).

Frente às mudanças sociais, políticas e culturais, Carvalho (4) afirma que, em decorrência do esgotamento do paradigma biomédico, na atualidade, o projeto da Promoção à Saúde desenvolve-se como resposta aos desafios sanitários contemporâneos. Dessa forma, com o advento do Sistema Único de Saúde, na forma em que foi concebido, a partir do impulso do processo da Reforma Sanitária, estabeleceu-se o desafio da mudança do paradigma da saúde. Essa mudança envolve um novo modo de pensar a saúde, o qual somente se processará com o envolvimento e o esforço de todos os atores envolvidos no processo: gestores, profissionais e usuários (3).

Após 26 anos de sua promulgação e da criação do SUS, observam-se avanços, dificuldades, insucessos e perspectivas no campo da saúde. Nesse cenário, a participação social institucionalizada em conselhos de saúde se constitui, por vezes, como poder fiscalizador voltado prioritariamente para o controle das contas públicas do Executivo e, por outras, como a participação na formulação das políticas e na escolha das prioridades de governo (5).

Nesse cenário, Correia (6) ressalta que a institucionalização da participação social foi resultado da articulação entre demandas sociais e ações do Estado. Assim, o conselho de saúde é considerado um dos principais órgãos de controle social dentro do SUS, criado a partir da promulgação Lei 8142/1990. No contexto do SUS, o controle social tem como foco principal sua defesa e resgate dos princípios constitucionais de universalidade, integralidade e acesso igualitário a todos os níveis de complexidade do sistema (6).

Gonçalves e cols. (7) afirmam que os conselhos de saúde se consolidaram como espaços legítimos de participação e articulação de diversos segmentos sociais, a partir da implementação do SUS. Entretanto, nos últimos anos, a trajetória do movimento participativo pela saúde pública no Brasil foi permeada por evoluções e retrocessos e buscou uma identidade que lhe assegurasse maior legitimidade no contexto das políticas sociais.

O Distrito Federal divide-se atualmente em 31 regiões administrativas e sua população é de 2.570.160 habitantes, segundo dados do Instituto Brasileiro de Geografia e 
Estatística (IBGE). O território do DF é dividido em 7 regiões de saúde (norte, sul, leste, oeste, centro-norte, sudeste e centro-sul) e atualmente cada região administrativa possui Conselho Regional de Saúde, além do Conselho de Saúde do DF (8).

No Distrito Federal, os conselhos de saúde se constituíram estratégias capazes de elencar prioridades e impulsionar a formulação de políticas na promoção da saúde como um direito, baseado na democracia participativa, por meio da criação de espaços para fiscalização de ações e controle social (6). Assim, a promulgação da lei 8.142/90 foi crucial para a organização do Sistema Único de Saúde, pautada no controle social exercido pelos conselhos de saúde.

No entanto, quanto à legislação, apesar da potencialidade transformadora dos conselhos, ainda existem entraves que necessitam de melhor avaliação, por impedirem a execução dos princípios preconizados pelo SUS. Estudos apontam a fragilidade nas formas de organização dos conselhos no Brasil, assim como assinalam a maior necessidade de estudos mais profundos, os quais sistematizem os fundamentos que norteiam a organização desses conselhos $(9,10,7)$.

Diante desse contexto, surge o questionamento: Quais as principais mudanças ocorridas nos dispositivos legais que regulamentam o Conselho de Saúde do Distrito Federal? Visando responder à pergunta investigativa, a pesquisa teve como objetivo discutir as principais mudanças ocorridas nos dispositivos legais que regulamentam o Conselho de Saúde do DF, à luz da Lei no 8.142/90.

\section{Metodologia}

Tratou-se de estudo exploratório descritivo, analítico e retrospectivo com abordagem quanti-qualitativa. Segundo Gil (11), as pesquisas exploratórias têm como principal finalidade desenvolver, esclarecer e modificar conceitos e ideias, tendo em vista a formulação de problemas mais preciosos ou hipóteses pesquisáveis para estudos posteriores. São desenvolvidas com o objetivo de proporcionar visão geral, de tipo aproximativo, acerca de determinado fato. Sobre os estudos descritivos, o autor destaca que essas pesquisas visam descobrir associações entre variáveis para elucidar determinados resultados por meio de técnicas padronizadas de coletas de dados.

Utilizou-se a técnica de análise documental das publicações no Diário Oficial do DF das resoluções e demais atos de criação do Conselho de Saúde do DF, assim como a 
legislação vigente acerca da organização e funcionamento do respectivo conselho.

A investigação foi realizada em setembro de 2014 e o campo de estudo foi a Secretaria Executiva do Conselho de Saúde do DF, por ser a instituição que delibera, por meio de atos e resoluções, o encaminhamento das demandas após reunião do pleno. Paralelamente, foi utilizado o site oficial do Conselho de Saúde do DF, assim como o acervo de atos e resoluções publicados no Diário Oficial do DF e que versam sobre o tema no período 1973 - ano de criação do Conselho de Saúde do DF - a 2011. O período do recorte da pesquisa foi escolhido em função do marco inicial do surgimento do conselho de saúde e a última alteração referente à sua organização e composição.

Utilizaram-se informações oriundas de 6 atos normativos da referida instituição, publicados no Diário Oficial do DF no período 1973 a julho de 2011. Para análise descritiva, foram levantadas as seguintes categorias: epígrafe; data de publicação; autoria e ano de publicação. Os achados foram tabulados em planilha eletrônica Microsoft Excel para análise e resultados.

A discussão dos resultados foi norteada por quatro principais temáticas: composição, com enfoque na representatividade e na paridade; atribuições; autonomia e participação nas decisões políticas.

\section{Resultados e discussão}

Os 5 atos normativos analisados (Quadro 1) possibilitaram observar a evolução legislativa do Conselho de Saúde do DF desde 1973, ano de sua criação, até 2011, data da última alteração legislativa responsável pela sua organização, composição e atribuições.

Quadro 1. Atos Normativos relativos ao Conselho de Saúde do DF

\begin{tabular}{|l|l|c|}
\hline Tipo de ato normativo & \multicolumn{1}{|c|}{ Epígrafe } & Autoria \\
\hline Decreto nº 2.225/1973 & $\begin{array}{l}\text { Cria, na Secretaria de Saúde, O Conselho de Saúde do DF, } \\
\text { com a atribuição específica de deliberar sobre matéria que Ihe } \\
\text { seja submetida, com a possibilidade de propor medidas de } \\
\text { interesse na formação da política local de saúde e na } \\
\text { coordenação infrassetorial. }\end{array}$ & \\
\hline Lei no 070/ 1989 & $\begin{array}{l}\text { Altera as atribuições e a composição do Conselho de Saúde } \\
\text { do DF, dispõe sobre vários colegiados da estrutura } \\
\text { administrativa do GDF, dá outras providências. }\end{array}$ & Poder Executivo DF \\
\hline Lei no 469/1993 & $\begin{array}{l}\text { Altera as atribuições e composição do Conselho de Saúde do } \\
\text { DF e modifica a Lei no 70, de 22 de dezembro de 1989, a fim } \\
\text { de implementar as recomendações da Resolução no 333, de } \\
\text { 22 de dezembro de 1992 do Conselho Nacional de Saúde. }\end{array}$ & Poder Executivo DF \\
\hline Lei no 2.413/1999 & $\begin{array}{l}\text { Altera o dispositivo da Lei 469, de vinte e cinco de junho de } \\
\text { 1993. }\end{array}$ & Poder Executivo DF \\
\hline
\end{tabular}


Poder Executivo DF

.

Criado pelo Decreto no 2.225/1973 (12), em 28 de março de 1973, o Conselho de Saúde do DF foi classificado como órgão deliberativo coletivo de 2º grau, com a atribuição específica de deliberar sobre matéria que lhe fosse submetida, podendo propor medidas de interesse na formulação da política local de saúde e na coordenação infrassetorial.

Esse decreto definia a composição de 12 membros para o Conselho de Saúde do DF: desses, 6 colaboradores representantes da associação dos profissionais de saúde, associação médica, associação brasileira de odontologia, associação de enfermagem, sociedade veterinária do DF e associação brasiliense de hospitais, indicados pelas entidades e designados pelo Secretário de Saúde; e 6 membros efetivos, designados pelo governador do DF.

Nesse período, cabe ressaltar que o Brasil vivenciava os anos da ditadura militar. Correia (6) afirma que durante esse período, o controle social foi exercido exclusivamente pelo Estado sobre a sociedade civil, por meio de decretos secretos, atos institucionais e repressão a qualquer expressão política por parte da população.

Assim, pode-se observar que a participação da sociedade civil não constava no texto do decreto de criação do Conselho de Saúde do DF, ao passo que atribuía o direito a voto de desempate ao secretário estadual de Saúde (Art. $\left.2^{\circ}\right)$, além do veto às decisões unânimes do conselho (Art.10 $0^{\circ}$. Destaca-se ainda que o decreto assinalava a necessidade de representação das profissões de saúde na composição do conselho.

Carvalho (13) afirma que os conselhos de saúde possuem raízes nas lutas comunitárias por saúde dos anos 70 e proclamam a expressão institucional de uma das ideias fundadoras da Reforma Sanitária: a participação da sociedade nas políticas e organizações de saúde. Pedro Demo (14) discute o tema da participação social pela perspectiva da emancipação, fundamental para alterar as relações de poder na sociedade, em busca de maior equidade e justiça social. Esse autor defende ainda participação como conquista, diferente de concessão ou algo preexistente.

Embora assumindo significados diversos ao longo do tempo, aos quais 
corresponderam padrões distintos de práticas sociais, o tema da participação esteve constantemente presente na retórica e na prática do movimento sanitário e atestou a íntima associação entre o social e o político que, no Brasil, tem caracterizado a agenda reformadora da saúde (13).

Nesse contexto, Paim e cols. (15) afirmam que a construção do sistema de saúde brasileiro foi fortemente influenciada pelos diferentes períodos históricos que o país viveu. Os autores afirmam ainda que a proposta da reforma sanitária brasileira começou a ganhar forma nesse período, estruturando-se durante a luta pela redemocratização do país e que se começou a cogitar a participação da sociedade nas decisões sobre a saúde nesse momento, como forma de garantir mudanças às políticas e às práticas até então existentes.

Correia (6) ressalta que na década de 1980 a relação entre Estado e sociedade indica mudança: de um lado, o Estado passa a reconhecer os movimentos sociais como interlocutores coletivos e responde a algumas de suas demandas; do outro, esses movimentos admitem negociar com o Estado por meio da política pública. Nesse período, o país vivenciou um quadro caótico e a partir dele o movimento pela Reforma Sanitária brasileira passou a formular alternativas para a política de saúde vigente (6).

Dessa forma, somente após a redemocratização do país deu-se a primeira alteração do Conselho de Saúde do DF, instituída pela Lei ํำ 70, de 22 de janeiro de 1989, a qual alterou as atribuições e a composição do conselho, além de modificar o quantitativo dos seus membros. Passou a ser composto por 17 membros, metade composta por entes ligados ao governo e prestadores de serviços de saúde e metade por representantes da sociedade civil. Além disso, o texto dessa lei conferiu ao Secretário de Saúde do DF a condição de membro nato (16).

Art. 2o - O Conselho de Saúde do Distrito Federal terá a seguinte composição:

I - Três Representantes da Secretaria de Saúde;

II - Um representante do Ministério da Saúde;

III - Um representante do Ministério da Previdência e Assistência Social;

IV - Um representante do Ministério da Educação;

V - Um representante do Ministério do Trabalho;

VI - Um representante dos prestadores de serviço de saúde que não integram o Sistema de Saúde;

VII - oito representantes da comunidade. 
A Constituição Brasileira, promulgada em 1989, apresenta como exigência a participação da comunidade, colocada como princípio de organização do sistema público de saúde (17). Logo, em resposta à necessidade de racionalização, deve-se organizar o sistema de saúde de acordo com a diretriz de descentralização, com direção única em cada esfera de governo, o que implica fomento da participação da comunidade nesse processo (18).

Dessa forma, um ano após a promulgação da Constituição, pôde-se observar avanço considerável na legislação que regulamenta a estrutura do Conselho de Saúde do DF, com a incorporação de membros da comunidade em sua composição de forma paritária em relação aos demais. Entretanto, em relação à representatividade das profissões da saúde, houve redução do número dessas na composição, uma vez que a Lei no 70/1989 não especifica quais categorias de saúde deveriam compor o conselho de saúde.

Kruger (19) defende que os conselhos de saúde estão sendo considerados como um novo lócus no exercício do poder político e, por estarem participando da gestão das políticas públicas, têm como proposta o estabelecimento de relação de outra natureza entre Estado e sociedade, pela qual os componentes para a construção de uma cultura política democrática e participativa estão colocados em posição privilegiada. Para isso, as condições para inserção paritária e a explicitação dos interesses dos vários segmentos sociais no âmbito das deliberações são indispensáveis para o acompanhamento e controle das ações do poder público.

Assim, a incorporação de membros da comunidade na composição do Conselho de Saúde do DF, de forma paritária, representa um avanço na estrutura desse conselho, o qual tem impacto direto nas suas deliberações.

Santos e Magalhães (20) afirmam que a democracia e suas facetas exigem do Estado a capacidade de elencar todas as expressões sociais e, nesse sentido, toda a diversidade de interesses e desejos de seus membros. Essa complexidade requer instrumentos e até mesmo certo grau de institucionalização que permitam atuar sob a perspectiva de solução de conflitos sociais ou no encaminhamento adequado das diversas demandas e plurais interesses. Logo, pode-se inferir que a redução da representatividade das profissões de saúde no conselho, instituída pela Lei no 70/1989, representa retrocesso legal com implicação direta na efetivação da democracia. 
No que diz respeito às atribuições do conselho de saúde, observa-se o disposto no Artigo 1ํ da Lei 70/1989 (16):

Art. 1ํ - Ao Conselho de Saúde do Distrito Federal, órgão de deliberação coletiva integrante da estrutura administrativa da Secretaria de Saúde, criado através do Decreto oㅡ 2.225, de 28 de março de 1973, compete:

I - Definir a política e as diretrizes gerais a serem adotadas no setor de saúde;

II - Aprovar os planos e programas de saúde;

III - opinar sobre projetos de lei a serem encaminhados à Casa Legislativa do Distrito Federal, quando a matéria Ihe for encaminhada;

IV - Definir a inter-relação que deve existir entre os diversos serviços de saúde, incluindo os dos setores público e privado;

$\mathrm{V}$ - Deliberar sobre quaisquer outros assuntos que interessem ao setor de saúde, desde que submetidos à sua apreciação, na forma regimental

Observa-se, pois, que esse dispositivo ampliou as competências do conselho de saúde em relação ao decreto de sua criação, ao passo que trouxe alguns avanços nesse campo, como a maior atuação do conselho na definição das políticas e diretrizes do setor saúde. Levando-se em consideração que esse dispositivo incluiu a comunidade como membro do conselho, Crevelim e Peduzzi (21), avaliam que o tema da participação da sociedade civil na esfera pública ganha dimensão no contexto da possibilidade de elaboração de políticas para inclusão de setores excluídos social e economicamente da realidade brasileira. Logo, em processos de deliberações e decisões dos destinos das políticas governamentais, recoloca e repõe a constituição dos sujeitos para a construção de projetos democráticos.

Assim, Teixeira e cols. (22) ratificam que a construção do Sistema Único de Saúde vem sendo marcada pela elaboração e implementação de instrumentos legais e normativos, cujo propósito central é garantir o direito à saúde preconizado pela Constituição Federal de 1988, assim como racionalizar as formas de financiamento e gestão dos sistemas estaduais e municipais de saúde, fundamentados em uma proposta de ampliação da autonomia política dos municípios.

Nesse sentido, a promulgação da Lei 8.080, de 19 de setembro de 1990, dentre outros fatores, dispõe sobre as condições para a promoção, proteção e recuperação da saúde, a organização e o funcionamento dos serviços correspondentes, os objetivos e atribuições o SUS (23), enquanto a Lei 8.142, de 28 de dezembro de 1990, regulamenta a 
participação da comunidade no SUS, a partir de instâncias colegiadas representadas pela Conferência de Saúde e pelo conselho de saúde, em cada esfera de governo, define os conselhos de saúde como órgãos permanentes e deliberativos, constituídos a partir de representação paritária dos governos respectivos, dos prestadores de serviços e dos usuários, cabendo-Ihes a formulação de estratégias e fiscalização da execução das políticas em cada esfera (24).

Teixeira e Solla (25) afirmam que a aprovação das Leis 8080/1990 e 8142/1990, principalmente o desencadeamento da municipalização das ações e serviços, acarretou expansão significativa dos espaços de participação social e consequente mudanças na organização e práticas dos serviços de saúde. Por conseguinte, deu-se a ampliação do campo de experimentação e multiplicação das alternativas de organização dos serviços e das práticas de participação social no âmbito do SUS.

Souza (26) afirma que um dos principais avanços da implementação do SUS, na década de 1990, esteve relacionado ao acelerado processo de descentralização políticoadministrativa, com progressiva transferência de responsabilidades e recursos do nível federal para o estadual, municipal e para o distrito federal. Nesse contexto, a participação social por meio dos conselhos de saúde, estabelecida como condição para os estados, municípios e distrito federal na implantação da descentralização, representaram importante instrumento de reorganização desse processo.

Desse modo, na década de 1990, quatro anos após a promulgação da Lei nº 70/1989, o governo do DF sanciona a Lei no 469, de 25 de junho de 1993, que altera as atribuições e composição do Conselho de Saúde do DF, com o propósito de implementar as recomendações da Lei 8142/1990, assim como a Resolução nº 033/92 do Conselho Nacional de Saúde - CNS (revogada pela Resolução do CNS n. ํ 453/2012, de 10 de maio de 2012). Dessa forma, a composição do Conselho de Saúde do DF permaneceu com 17 membros, entretanto, observando o disposto no Art. $1^{\circ}$ da referida lei, que institui que a representação dos usuários nos conselhos de saúde deverá ser paritária em relação ao conjunto dos demais segmentos. Assim, o Conselho de Saúde do DF passou a funcionar com 4 representantes dos prestadores de serviços, 4 representantes dos trabalhadores, 8 representantes dos usuários e o secretário de saúde na condição de Presidente (Art. $2^{\circ}$ ).

Além disso, a Lei 469/1993 (27), ampliou as competências do Conselho de Saúde do DF, a qual determina, no Artigo $3^{\circ}$, dentre outras atribuições, a competência do conselho 
de saúde para propor a convocação e estruturar a comissão organizadora das Conferências Distritais de Saúde; estimular a participação comunitária no controle da administração da saúde; assim como elaborar e alterar, quando necessário, o regimento interno do conselho e suas normas de funcionamento, a demonstrar considerável avanço no que se refere à sua autonomia.

Os conselhos podem se configurar como instrumentos privilegiados para fazer valer os direitos, romper com as tradicionais formas de gestão, possibilitar a ampliação dos espaços de decisões/ações do poder público, impulsionar a constituição de esferas públicas democráticas e potencialmente capacitarem os sujeitos sociais para processos participativos mais amplos e de interlocução ético-política com o Estado (19). Entretanto, estudos têm demonstrado que apenas a existência formal dos espaços de controle social não assegura a participação política da sociedade. Os conselhos de saúde, em maior ou menor grau, apresentam uma série de problemas que comprometem sua eficácia (28).

A terceira alteração do Conselho de Saúde do DF foi instituída pela Lei oㅡ 2.413, 29 de junho de 1999, que modificou o Art. $1^{\circ}$ da Lei ํㅡ 469/1993. Com a mudança, o conselho passou a ser composto por 10 membros; desses, 3 representantes dos prestadores de serviço; 2 representantes dos trabalhadores, indicados pelas entidades dos sindicatos de classes representativas do setor; 5 representantes dos usuários, dos quais 1 representante da Associação dos Portadores de Necessidades Especiais, 1 representante da Associação de Portadores de Patologias, 1 representante da entidade de Defesa do Consumidor, 2 representantes dos conselhos comunitários, associação de moradores ou equivalentes; além do presidente, na condição de secretário e de membro nato com direito a voto de quantidade e qualidade.

A quarta alteração do Conselho de Saúde do DF deu-se pela Lei o 4604, de 15 de julho de 2011, que modificou o dispositivo da Lei no 2.413/1999 e revogou todos os dispositivos legais anteriores. Essa Lei está em vigor e dispõe sobre a organização, a composição e as atribuições do Conselho de Saúde do DF. Esse dispositivo legal foi elaborado em conformidade com o art. 198, III, da Constituição Federal; o art. 7º, VIII, da Lei o 8.080, de 19 de setembro de 1990; a Lei Federal o 8.142, de 28 de dezembro de 1990; o art. 215 da Lei Orgânica do Distrito Federal; e com as diretrizes da Resolução no 333 do Conselho Nacional de Saúde, de 4 de novembro de 2003.

Art. 1ํ O Conselho de Saúde do Distrito Federal, órgão colegiado, de 
caráter permanente e deliberativo, integrante da estrutura regimental da Secretaria de Saúde do Distrito Federal, é composto por representantes do governo e prestadores de serviço, profissionais de saúde e usuários, cujas decisões, consubstanciadas em resoluções, são homologadas pelo Secretário de Saúde do Distrito Federal.

Parágrafo único. O Conselho de Saúde do DF atua na formulação e proposição de estratégias e no controle da execução das políticas de saúde, no âmbito do Distrito Federal, inclusive em seus aspectos econômico-financeiros e nas estratégias para a sua aplicação aos setores públicos e privados.

A composição do Conselho de Saúde do DF, modificada em 2011, foi fruto de longa negociação da sociedade civil, entidades de trabalhadores e gestores da Saúde (26). A partir da Lei 4604/2011 (29), o presidente do conselho passou a ser eleito pelos seus membros, cargo até então ocupado pelo Secretário de Estado da Saúde do DF, na condição de membro nato. Além disso, essa lei ampliou de forma considerável a composição do conselho, a qual passou de 10 membros, na última legislação vigente, para 28 membros, com significativa representatividade.

A partir dos notáveis avanços nos atos normativos dos conselhos de saúde, no plano legislativo que regulamenta o setor saúde, é evidente que os dispositivos constitucionais e a legislação ordinária organizaram mecanismos adequados para o exercício da verdadeira participação social (29). Entretanto, Costa e Noronha (3) ressaltam que, apesar da organização da esfera normativa, acumularam-se nesse setor muitos avanços e mudanças que ainda não se processaram no âmbito operativo da atenção à saúde.

Nesse contexto, Delduque e Bardal (30) afirmam que a participação social no Brasil ainda é bastante incipiente. No campo da saúde, embora assegurada constitucionalmente a participação popular nas políticas públicas sanitárias, não há evidências "maduras" dessa experiência democrática na realidade brasileira. A dificuldade de definição do desempenho dos conselhos, a dificuldade de construir indicadores úteis e confiáveis para comparar uma amostra razoável de casos e a enorme quantidade de conselhos hoje existentes estão entre os principais obstáculos para avaliarmos o impacto real dos conselhos no Sistema Único de Saúde (3).

Guizardi (26) assinala que os conselhos não conseguem garantir a democratização das políticas, ao passo que apresentam dificuldades de se apresentarem de forma permeável aos distintos segmentos e setores sociais implicados, sem que os diferentes 
interesses se apresentem e se afirmem nos espaços de negociação e pactuação. Assim, a falta de divulgação, transparência e informações sobre os conselhos caracterizam-se como problemas diretamente relacionados à comunicação com a sociedade e, em certa medida, intimamente atrelados às limitações na representatividade dos conselheiros.

Ainda assim, é importante ratificar a discussão sobre o processo de criação e reorganização dos conselhos de saúde no Brasil e sua importância para a participação da sociedade civil na tomada de decisão como elemento primordial no processo de construção da cidadania, além de se constituir instrumento de controle social e mecanismo estratégico na garantia do direito à saúde, fundamentado nos princípios da democratização no Sistema Único de Saúde (31).

Além disso, Correia (3) pondera que tanto os usuários quanto os gestores do SUS não possuem conhecimento satisfatório sobre o papel e importância dos conselhos. Essa realidade se configura como fator limitante à implantação do princípio da participação social nos municípios brasileiros, uma vez que os conselhos de saúde, no exercício de suas funções, demandam dos cidadãos a crescente capacidade de atuar politicamente, promover negociações, resolver conflitos, fiscalizar e estabelecer prioridades no campo da saúde.

Ademais, o espaço dos conselhos de saúde comporta conflitos, resistências e tensões permanentes, assim como soluções criativas, as quais podem ser combinadas no processo de apropriação social dos espaços públicos na substituição da cultura política tradicional (19).

\section{Conclusões}

Observou-se que as principais mudanças ocorridas nos dispositivos legais que regulamentam o Conselho de Saúde do DF estão fortemente associadas ao contexto político que o país vivenciou nas últimas décadas. Cabe ressaltar a importância do movimento de redemocratização do país e a reforma sanitária brasileira nesse processo, uma vez que esses movimentos fomentaram e desencadearam as mudanças expressivas na legislação do Conselho de Saúde do DF.

As principais alterações nos instrumentos legais que regulamentam o Conselho de Saúde do DF decorreram da tentativa de atender a demandas que surgiram a partir da promulgação da Constituição Federal, que inaugurou um novo ordenamento jurídico e 
político e, posteriormente, das Leis 8080/1990 e 8142/1990, cujos textos estabelecem a necessidade de se criarem espaços de participação social no SUS e de se estabelecerem canais de negociação e efetivação do controle social. Logo, a origem e a evolução do Conselho de Saúde do DF estão associadas aos diversos momentos históricos que o país viveu, os quais foram marcados pelos desafios e pelas conquistas enfrentadas pela sociedade brasileira no campo da política.

Observam-se limitações nos textos dos atos normativos analisados, centrados principalmente na alteração da estrutura, composição e competências do Conselho de Saúde do DF, apesar das alterações implementadas principalmente a partir da criação do SUS. Além disso, nota-se ainda acentuada demora na regulamentação das alterações legislativas para conformar-se com a Constituição de 1988, bem como com os dispositivos legais do âmbito federal. Vale ressaltar que a existência somente dos dispositivos legais não assegura a existência concreta do conselho, na forma como está preconizado na legislação e, ainda que o conselho se concretize em espaços formais, esses não asseguram a participação efetiva da sociedade no SUS.

\section{Referências}

1 Dallari, SG; Adorno, RCF; Faria, MMO ; Shugair, NSMSAQ; Trewikowski, S. direito à saúde na visão de um conselho municipal de saúde. Rev. Cad. Saúde pública 4 (12):531540 1996. Disponível em:

http://www.scielo.br/scielo.php?script=sci_arttext\&pid=s0102311x1996000400012 \&lng=en\&nrm=iso. [Acesso em 3 de out 2014].

2 Paim, JS; Teixeira, CF. Configuração Institucional e gestão do sistema único de saúde: problemas e desafios. Rev. Ciênc. Saúde coletiva 3 (12): 1819-182, 200. Disponível em: http://www.scielo.br/scielo.php?script=sci_arttext\&pid=s1413-

$81232007000700005 \& \operatorname{lng}=$ en\&nrm=iso. [Äcesso em 3 out 2014].

3 Costa, AM. E Noronha, JC. Controle social na saúde: construindo a gestão participativa. Rev. Saúde em debate 27 (65): 58-363, 2003, Disponível em:

http://bases.bireme.br/cgibin/wxislind.exe/iah/online/?isisscript=iah/iah.xis\&src=go ogle\&base=lilacs\&lang=p\&nextaction=Ink\&exprsearch=394037\&indexsearch=id [Acesso em 3 de out 2014].

4 Carvalho, SR. Os múltiplos sentidos da categoria "empowerment" no projeto de promoção à saúde. Cad. Saúde pública 20 (4): 1088-1095, 2004. Disponível em: http://www.scielosp.org/scielo.php?script=sci_arttext\&pid=s0102-

$311 \times 2004000400024 \&$ Ing=en\&nrm=iso. [Acesso em 3 out 2014]. 
5 Escorel, S; Delgado, MM. Perfil dos conselhos estaduais de saúde: singularidades e similaridades no controle social. Rev. Divulg. Saúde debate (43): 62-78, 2008. Disponível em: http://www.cebes.org.br/internaeditoria. asp?idconteudo=118\&idsubcategoria=21 . [Acesso em 3 out 2014].

6 Correia, MVC. Desafios para o controle social: subsídios para capacitação de conselheiros de saúde. Rio de Janeiro: Fiocruz; 2003

7 Gonçalves, AO. Et al. Contribuições da gestão participativa no espaço público chamado conselho: o contexto dos conselhos de saúde no brasil. Revista divulgação em saúde para debate (43): 3-6, 2008. Disponível em:

http://observasaude.fundap.sp.gov.br/saude2/saudepublica/acervo/democracia\%2e\%20con selho\%20saude.pdf. [Acesso em 3 out 2014].

8 Distrito Federal. Secretaria de Estado de Planejamento e Orçamento do Distrito Federal. Companhia de Planejamento do Distrito Federal. Pesquisa distrital por amostra de domicílios - Distrito Federal 2011.

9 Ceccim, RB. E Feuerwerker, LCM. O quadrilátero da formação para a área da saúde: ensino, gestão, atenção e controle social. Revista Physis 14 (1): 41-65, 2004.

10 Dallari, SG. A participação popular e o direito à saúde no sistema nacional de saúde brasileiro. Revista de direito sanitário, 6 (1/2/3):9-24,2005. Disponível em: http://www.revistas.usp.br/rdisan/article/view/80811/84458. [ Acesso em 3 out 2014].

11 Gil, AC. Como elaborar projetos de pesquisa. 5.ed. São Paulo: Atlas, 1999.

12 Distrito Federal. Decreto oㅡ 2.225, de 28 de março de 1973. Cria, na secretaria de saúde, o conselho de saúde do Distrito Federal. Brasília, DF, 28 de março de 1973. Disponível em acervo impresso da secretaria de saúde do DF. [Acesso em 10 set 2014]

13 Carvalho, Al. Conselhos de saúde, responsabilidade pública e cidadania: a reforma sanitária como reforma do estado. In: Fleury, Sônia m. T. (org.). Saúde e democracia: a luta do Cebes. São Paulo: Lemos editorial: 1997

14 Demo, P. Participação é conquista. São Paulo: Corte: 1993.

15 Paim,JS et al. O sistema de saúde brasileiro: história, avanços e desafios. In: séries de seis fascículos em saúde no brasil, the Lancet (1): 11-31, 2011. Disponível em:

http://download.thelancet.com/flatcontentassets/pdfs/brazil/brazilpor1.pdf. [Acesso em 3 out 2014].

16 Distrito Federal. Lei o 70, de 22 de janeiro de 1989. Poder executivo DF. Altera as atribuições e a composição do conselho de saúde do distrito federal, dispõe sobre vários colegiados da estrutura administrativa do GDF dá outras providências. Brasília, DF 22 de janeiro de 1989. Disponível em acervo impresso da secretaria de saúde do DF [Acesso em 10 set 2014]

17 Brasil. Constituição (1988). Constituição da República Federativa do Brasil. Brasília, DF: Senado Federal, 2000. 
18 Vázquez ML; Silva, MRF, Gonzalez, ESC; Diniz, AS; Pereira, APC; Veras, ICL . Nível de informação da população e utilização dos mecanismos institucionais de participação social em saúde em dois municípios do Nordeste do Brasil. Ciênc. saúde coletiva, 10: 141155, 2005. Disponível em: http://www.scielo.br/scielo.php?script=sci_arttext\&pid=S1413$81232005000500017 \&$ lng=en. [Acesso em 3 out 2014].

19 Kruger, TR. O desconhecimento da reforma sanitária e da legislação do sus na prática do conselho de saúde. Rev. planejamento e políticas públicas-Ipea 22(22):119-44,200. Disponível em: http://www.ipea.gov.br/ppp/index.php/ppp/article/viewfile/82/162.. [Acesso em 10 out 2014].

20 Santos, BM. E Magalhães, JIQ. De. Notas para um debate princípio lógico sobre participação à luz de uma teoria democrática. Revista brasileira de políticas públicas. 1 (2): 1-30,2011. Disponível em:

http://www.publicacoesacademicas.uniceub.br/index.php/rbpp/article/view/1220. [Acesso em 3 out 2014].

21 Crevelim, MA. E Peduzzi, M. Participação da comunidade na equipe de saúde da família: é possível estabelecer um projeto comum entre trabalhadores e usuários? Rev. Ciência \& Saúde Coletiva, 10 (2): 323-331,2005. Disponível em: http://www.scielo.br/scielo.php?script=sci_arttext\&pid=s1413$81232005000200010 \& \operatorname{lng}=e n \& n r m=i s o$. [Äcesso em 3 out 2014].

22 Teixeira, CF.; Paim JS. E Vilasbôas, AIQ. Sus, modelos assistenciais e vigilância da saúde. Informe epidemiológico SUS 7 (2):7-2, 1998.]. Disponível em: http://scielo.iec.pa.gov.br/scielo.php?pid=s0104-16731998000200003\&script=sci_arttext. [Acesso em 3 out 2014

23 Brasil. Presidência da República. Diário oficial da União. Lei № 8080, de 19 de setembro de 1990. Dispõe sobre as condições para promoção, proteção e recuperação da saúde, a organização e o financiamento dos serviços correspondentes e dá outras providências. Brasília, DF, 1990. Disponível em: http://www.planalto.gov.br/ccivil_03/leis/l8080.htm. [Acesso em 20 set de 2014].

24 Brasil. Presidência da República. Diário oficial da União. Lei no 8142, de 28 de dezembro de 1990. Dispõe sobre a participação da comunidade na gestão do sistema único de saúde (SUS) e sobre as transferências intergovernamentais de recursos financeiros na área da saúde e dá outras providências. Brasília, DF, 1990. Disponível em: http://www.planalto.gov.br/ccivil_03/leis/l8142.htm. [Acesso em 20 set. 2014].

25 Teixeira, CF.; Solla, J. P. Modelo de atenção à saúde: Promoção, vigilância e saúde da família. Salvador: EDUFBA, 2006.

26 Souza, RA regionalização no contexto atual das políticas de saúde. Revista ciênc. Saúde coletiva 6(2): 451, 2001. Disponível em: http://www.scielo.br/scielo.php?script=sci arttext\&pid=s1413-81232001000200014. [ Acesso em 3 out 2014].

27 Distrito Federal. Lei ํㅜ 469, de 25 de junho de 1993. Altera as atribuições e composição 
do conselho de saúde do DF, modificando a Lei oㅡ 70, de 22 de dezembro de 1989, com o propósito de implementar as recomendações da Resolução no 333 de 22 de dezembro de 1992 do Conselho Nacional de Saúde. Disponível em:

http://www.tc.df.gov.br/sinj/arquivo.ashx?id_norma_consolidado=48428. . [Acesso em 24 set. 2014].

28 Guizardi, F L.; Pinheiro, R.; Mattos, R A.; Santana, S. D.; Matta, G; Gomes, M. C.P.A. Participação da comunidade em espaços públicos: uma análise das conferências nacionais de saúde. Physis 1(14):15-39,2004. Disponível em:

http://www.scielo.br/scielo.php?pid=S0103-73312004000100003\&script=sci arttext [Acesso em 3 out 2014].

29 Distrito Federal. Lei o 4604, de 15 de julho de 2011. Dispõe sobre a organização, a composição e as atribuições do Conselho de Saúde do Distrito Federal. Brasília, DF,2011. Disponível em:

http://www.saude.df.gov.br/images/conselho\%20de\%20saude\%20do\%20df/legisl acao/lei_4604___dodf.pdf. [ Acesso em 24 set 2014].

30 Delduque, MC; Bardal P.A.P. Advocacia em saúde: prática cidadã para a garantia do direito à saúde - o caso do projeto de lei complementar. Revista de direito sanitário 9 (1): 107-122, 2008. Disponível em: http://www.revistas.usp.br/rdisan/article/view/80811/84458. [Acesso em 3 out 2014].

31 Martins, PC. Conselhos de saúde e a participação social no Brasil: matizes da utopia. Revista Physis 18 (1): 47-65, 2008. Disponível em: http://www.scielo.br/scielo.php?script=sci_arttext\&pid=s010373312008000100007 \&lng=en\&nrm=isso. [Acesso em 3 out 2014].

\section{Como citar este artigo:}

Gomes ML, Alves SMC. Conselho de saúde do Distrito Federal: uma análise documental. Revista Cadernos Ibero-Americanos de Direito Sanitário. 2016 out./dez, 5(4):59-75. 